\title{
Activity as a function of genetic variables and opportunity for exploration
}

\author{
DUDLEY F. PEELER, JR. \\ Department of Neurosurgery \\ University of Mississippi Medical Center, Jackson, Miss. 39216
}

Mice of C57BL/6 and CF1 strains, and their hybrids, were tested for amount of investigatory and locomotor activity in a runway in terms of object contacts and light beam interruptions, respectively. CF1 Ss exhibited higher levels of both types of activity than C57 Ss. Hybrids were similar to CF1s with respect to amount of locomotor activity, but most resembled C57s in terms of the shape of their activity curves. Hybrid Ss maintained a higher level of object contact activity than either of the other groups.

Mice of different laboratory strains have been found to exhibit characteristic differences in activity in a variety of measuring situations (e.g. see Fuller \& Thompson, 1960; McClearn, 1968; McClearn \& Meredith, 1966; Wimer \& Fuller, 1966). There are indications that different measurement techniques may actually provide indices of different types of activity (Guttman, Lieblich, \& Naftali, 1969; McClearn, 1959, 1968; McClearn \& Meredith, 1964). Although the most common technique involves determination of exploratory activity in some sort of arena or "open field," there are indications that one may differentiate activity into locomotion (general ambulation) and exploratory (investigatory) behaviors (Foshee, Vierck, Meier, \& Federspiel, 1965; Vanderpool \& Davis, 1962). Foshee et al (1965) report that investigation by mice of a specific object shows a different, more rapid rate of decline than does locomotion. They conclude from these findings that contact with a single object at the end of the runway is independent of locomotor activity throughout the runway. However, since in their study the opportunity for exploration, as measured by contact with the single object, was restricted to the small area at one end of the runway, this interpretation might be questioned. It is possible that object contacts and runway locomotion are both manifestations of the same investigatory activity but that, with much more area to be covered-with any of a multitude of possible stimuli to be investigated-overall runway activity would be expected to persist at a higher level than contact with any single object or place within the apparatus. If the differences between the two activity measures do not persist, when there is similar or equal opportunity for both types, then this dichotomy into "exploratory" and "general" activity might well be considered a function of apparatus rather than $\mathrm{S}$ variables.
Strains of laboratory mice may be ranked according to total amount of activity, and the importance of genotype in determining locomotor and exploratory activity in novel situations has been demonstrated (DeFries \& Hegmann, 1970; McClearn, 1959, 1960, 1961; Thompson, 1953, 1956; Vanderpool \& Davis, 1962). The great majority of investigations of activity in mice which have utilized inbred laboratory strains and their hybrids indicate that C57 strains are consistently more active with respect to a variety of behaviors, including open-field or exploratory activity, and that hybrids produce values ranging from intermediate to that of their parents (McClearn, 1961; Mordkoff \& Fuller, 1959), to scores comparable to that of the most active parent (DeFries \& Hegmann, 1970), to values that exceeded those of both parents (Bruell, 1967). Changes in the level of activity produced by each strain when tests were repeated over several days also have been interpreted as manifestations of genetic determination of behavior or of genetic-environmental interaction (Brookshire \& Rieser, 1967; Dixon \& DeFries, 1968; Weir \& DeFries, 1964).

Whereas the importance of studying the genetic contribution to behavior in other than highly inbred laboratory strains has been stressed (Bruell, 1967), relatively few studies include noninbred wild-type (Wolfe, 1969) or other genetically heterogeneous Ss (McClearn \& Meredith, 1964).

This study had the dual purpose of: (1) determining the relative stability of object-directed investigatory activity and locomotor runway activity in a situation providing more nearly equal opportunity for measuring both types of responses, and (2) gaining further insight into the nature of the genetic contribution to activity differences by using two laboratory mouse strains, one inbred and one noninbred, and their hybrids.

\section{METHOD}

Forty-two adult male mice were placed, 15 min daily, for 7 consecutive days, in a runway device of the same general dimensions as that used by Foshee et al (1965). The runway was $33.5 \mathrm{in}$. long, $4 \mathrm{in}$. wide, and $4 \mathrm{in}$. high, with three photocells and light sources aimed across the runway in the center and 7 in. from either end, respectively. However, instead of an object at one end, there was an array of 16 "free form" metal objects spaced evenly along one side. These were electrically insulated from the metal floor. The objects were designed such that there was insufficient space between them and the glass top of the runway for climbing. Physical contact by the mouse between the floor and any object completed a transistor trigger circuit which drove an electromagnetic counter. Interruption of a light beam also resulted in a count on an electromagnetic counter. The apparatus was dark except for the red lights aimed on the photocells. Counts were recorded from each of the counters at 5,10 , and 15 min after the session began. The runway was enclosed during testing in a sound-shielded box with low-pressure forced draft ventilation.

The Ss were housed in normal plastic laboratory cages in groups of six or four. They had continued free access to food and water. Light cycles were those of normal daylight and dark, provided through a skylight, with room lights on during normal working hours. All Ss were run during midafternoon.

The strains investigated were CF1,

Table 1

Locomotor and Investigatory Activity (Mean Number of Counts Per 5-M in Period) Over Days

\begin{tabular}{|c|c|c|c|c|c|c|c|c|}
\hline & & \multicolumn{7}{|c|}{ Day } \\
\hline & & 1 & 2 & 3 & 4 & 5 & 6 & 7 \\
\hline C57BL/6 & $\begin{array}{l}\mathrm{L}^{*} \\
\mathrm{O}^{*}\end{array}$ & $\begin{array}{l}69.0 \\
68.3\end{array}$ & $\begin{array}{l}53.5 \\
29.1\end{array}$ & $\begin{array}{l}49.2 \\
28.6\end{array}$ & $\begin{array}{l}51.1 \\
28.6\end{array}$ & $\begin{array}{l}55.5 \\
33.0\end{array}$ & $\begin{array}{l}59.4 \\
37.2\end{array}$ & $\begin{array}{l}51.8 \\
41.5\end{array}$ \\
\hline CF 1 & $\begin{array}{l}\mathrm{L} \\
\mathrm{O}\end{array}$ & $\begin{array}{l}76.3 \\
61.2\end{array}$ & $\begin{array}{l}74.1 \\
52.3\end{array}$ & $\begin{array}{l}77.4 \\
47.3\end{array}$ & $\begin{array}{l}63.5 \\
33.3\end{array}$ & $\begin{array}{l}64.5 \\
28.8\end{array}$ & $\begin{array}{l}71.5 \\
42.1\end{array}$ & $\begin{array}{l}67.5 \\
32.5\end{array}$ \\
\hline Hybrid & $\begin{array}{l}\mathbf{L} \\
\mathrm{O}\end{array}$ & $\begin{array}{l}98.6 \\
71.7\end{array}$ & $\begin{array}{l}67.4 \\
40.6\end{array}$ & $\begin{array}{l}63.4 \\
49.4\end{array}$ & $\begin{array}{l}62.9 \\
50.1\end{array}$ & $\begin{array}{l}60.2 \\
49.4\end{array}$ & $\begin{array}{l}70.2 \\
54.6\end{array}$ & $\begin{array}{l}66.8 \\
47.3\end{array}$ \\
\hline
\end{tabular}

$*_{L}=$ light beam crossings: $O=$ object contacts

Psychon. Sci., 1972, Vol. 27 
Table 2

Intrasession Locomotor and Investigatory Activity (Mean Number of Counts Per 5-Min Period)

\begin{tabular}{|c|c|c|c|c|}
\hline & & \multicolumn{3}{|c|}{$\begin{array}{l}\text { Intrasession } \\
\text { Time Periods } \\
\text { (5 Min Each) }\end{array}$} \\
\hline & & 1 & 2 & 3 \\
\hline C57BL/6 & $\begin{array}{l}L^{*} \\
O^{*}\end{array}$ & $\begin{array}{l}75.8 \\
50.8\end{array}$ & $\begin{array}{l}50.7 \\
35.4\end{array}$ & $\begin{array}{l}40.4 \\
28.0\end{array}$ \\
\hline CF1 & $\begin{array}{l}\mathrm{L} \\
\mathbf{O}\end{array}$ & $\begin{array}{l}96.1 \\
54.4\end{array}$ & $\begin{array}{l}62.6 \\
42.4\end{array}$ & $\begin{array}{l}53.4 \\
\mathbf{3 0 . 8}\end{array}$ \\
\hline Hybrid & $\begin{array}{l}L \\
O\end{array}$ & $\begin{array}{l}84.0 \\
56.6\end{array}$ & $\begin{array}{l}68.9 \\
53.7\end{array}$ & $\begin{array}{l}56.9 \\
45.4\end{array}$ \\
\hline
\end{tabular}

$* L=$ light beam crossings; $O=$ object contacts

C57BL/6, and hybrids resulting from crossing C57 males with CF1 females. There were 14 male mice in each of the three groups.

RESULTS AND DISCUSSION

The results were analyzed using a mixed design analysis of variance (Lindquist, 1953; Winer, 1962). CF1 mice were found to have higher overall activity level than C57s $(\mathrm{p}<.05)$. Mean activity counts per 5-min interval are shown in Table 1 for locomotor (light beam crossings) and investigatory (object contact) activity. This is contrary to the reports of other investigators in which $\mathrm{C57}$ animals are consistently more active than other strains in most types of activity (e.g., Guttman et al, 1969; McClearn, 1959, 1960,1968 ; Thompson, 1953, 1956; Wolfe, 1969). These results are also at variance with findings from the single-object situation (Foshee et al, 1965) in which CF1 and C57 mice were comparable in their object contacts. The hybrid animals registered more of both types of responses than did the $\mathrm{C57}$ mice (p<.001), but were not statistically different from the CF1s. Dixon \& DeFries (1968) report intermediate open-field activity for hybrids of Balb/cJ and C57BL/6J parents. Both object contact and light-beam crossing showed a significant decline in activity between $(p<.001)$ and within $(p<.001)$ sessions. These changes in activity over days may be seen in Table 1. The decline is relatively gradual for CF1 Ss, but shows a sharper decrease for C57s and hybrids. Note that, whereas the hybrids are essentially the same as CF1 mice in terms of light-beam crossing, their initial rate of decline most nearly resembles that of the $\mathrm{C57}$ strain. The scores from Table 1 show a similar relationship in object contact responses between strains. The hybrids are again very similar to the C57 strain in the initial rate of responding, but maintain a higher level of object-investigatory activity than either strain. This resulted in a significant interaction of Day by Strain by Type of Activity $(p<.01)$. For CF1 and C57 Ss, the initial decline in activity is more precipitate for object contact than for light-beam crossings. There are significant Day by Type of Activity interactions for the two strains $(\mathrm{p}<.001, \mathrm{p}<.025$, respectively), but not for the hybrid Ss. There is also a very interesting and consistent rise in both object contact and locomotor activity of all three groups on Day 6. However, it is not statistically significant.

All Ss showed the usual intrasession decline in both types of response $(\mathrm{p}<.001)$. In this respect, the CF1 and C57 mice had virtually identical changes in response rate, while maintaining their same relationship with respect to activity level. The hybrids, on the other hand, start at a comparable level of activity but show less rapid decline, resulting in an interaction between strain and time period within sessions. As may be seen in Table 2, the hybrid Ss maintain a higher activity level than the CF1 and C57 Ss in the later time periods. The hybrids and CF1 animals tend to show a greater intrasession decline in light beam crossings than in object contacts, while C57 Ss exhibit similar reductions in both types of activity within sessions $(p<.05)$. [The Type of Activity by Intrasession Time Periods interaction was significant for hybrid and CF1 groups $(p<.001)$, but not for C57 Ss.]

The variability of the three groups is of interest from the genetic standpoint: decreased variability of the hybrid mice could be interpreted as another indication of heterosis with respect to activity. A finding of differential variability in the strains and their hybrids with respect to the activity measures would substantiate for yet another activity measure the role of genetics as a determinant of mouse activity, and different orderings of the groups with respect to their variability in the two types of measurements would support the notion that two different types of activity are actually being measured.

With respect to light-beam crossings,

Table 3

Variability $\left(S^{2}\right)$ of Locomotor and Investigatory Activity

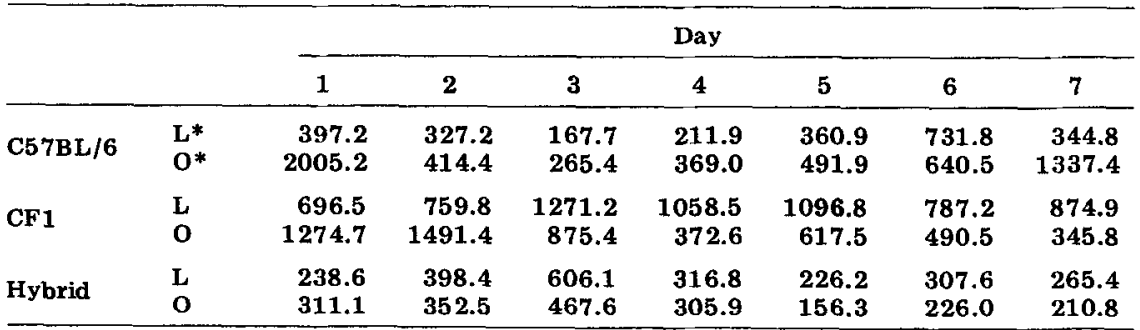

the mean activity scores and variances for C57, CF1, and hybrid Ss are $\mathbf{5 5 . 6}$ $(126.8), 70.7 \quad(485.4)$, and 69.9 (150.5), respectively. These variances are not heterogeneous at the .05 level, using the Fmax test. However, it is noteworthy that the variance for CF1 Ss is over three times that of either of the other two groups. The variances for daily performance are shown in Table 3. Only those variances for Days 3,4 , and 5 are heterogeneous at the .05 level or better. The hybrid Ss most nearly resemble the $\mathrm{C} 57 \mathrm{~s}$ in variability, whereas they are closest to the CF1 Ss with respect to level of locomotor activity.

With respect to object contacts, the variances are significantly different $(p<.01)$ on Days 1, 2, and 7. The hybrid Ss produce less variability than the other two groups on Days 1 and 7 , and less than the CF1s on Day 2. In terms of absolute variance, the hybrids are consistently less than the CF1 and C57 Ss on all 7 days. This is in direct contrast to variability for light beam crossings, where C57 and hybrid variances assume no definite order but are both consistently lower than that for CF1 animals. It is noteworthy that, whereas the hybrids tend to have lower variances, they have a higher level of object contact activity than the other two groups.

The variances for intrasession time periods are given in Table 4 . There is significant heterogeneity $(p<.05)$ in Period 3 for light-beam crossings, and in Periods $1(p<.01)$ and $3(p<.05)$ for object contacts.

The initial contention that runway locomotion and object contact both might be considered as exploratory activity, artificially dichotomized by measurement techniques, is not borne out by the present data. Rather, even with greatly increased opportunity for object investigation, a different rate of change over exposure time persists between investigation of specific objects and locomotion in a runway. Although showing some initial decline, runway locomotion remained relatively stable over time for all three groups, whereas object investigation declined, at least for two of the groups, at a more rapid rate and 
Table 4

Intrasession $V$ ariability $\left(S^{2}\right)$ of Locomotor and Investigatory Activity

\begin{tabular}{|c|c|c|c|c|}
\hline & & \multicolumn{3}{|c|}{ Intrasession Time Periods (5 Min Each) } \\
\hline & & 1 & 2 & 3 \\
\hline C57BL/6 & $\begin{array}{l}\mathrm{L}^{*} \\
\mathrm{O}^{*}\end{array}$ & $\begin{array}{l}386.1 \\
733.8\end{array}$ & $\begin{array}{l}130.0 \\
379.8\end{array}$ & $\begin{array}{l}128.3 \\
273.7\end{array}$ \\
\hline CF1 & $\begin{array}{l}\mathrm{L} \\
\mathrm{O}\end{array}$ & $\begin{array}{l}708.2 \\
267.9\end{array}$ & $\begin{array}{l}511.6 \\
368.6\end{array}$ & $\begin{array}{l}431.0 \\
266.0\end{array}$ \\
\hline Hybrid & $\begin{array}{l}\mathrm{L} \\
\mathrm{O}\end{array}$ & $\begin{array}{r}287.1 \\
86.2\end{array}$ & $\begin{array}{l}237.7 \\
209.2\end{array}$ & $\begin{array}{l}88.5 \\
54.9\end{array}$ \\
\hline
\end{tabular}

$* L=$ light beam crossings; $O=$ object contacts

appeared surprisingly independent of number and variety of stimuli and highly dependent upon length of exposure.

The extent and time course of both of these activities appear to be partially a function of genetic variables, which may combine to present behavior unlike that of either parent. The CF1-C57 hybrids exhibited a level of general activity comparable to that of CF1 mice, but most closely resembled the $\mathrm{C} 57 \mathrm{BL} / 6$ strain in their initial rate of decline and in their variability. Also, they maintained a higher level and lower variability of investigatory exploration than either of their parent strains. Thus, we may infer the strong probability of both directional dominance and a heterotic effect. Heterosis in measures of activity has been reported for wheel running and for exploratory activity (Bruell, 1964, 1967). The present results support these findings in terms of investigatory behavior as measured by object contacts, but not in terms of locomotion in a runway. This is consonant with the idea that the two types of behavior measured in this study-investigatory exploration and general locomotor activity-are, at least in part, manifestations of different determining factors.

\section{REFERENCES}

BROOKSHIRE, K. H., \& RIESER, T. C Temporal course of exploratory activity in three inbred strains of mice. Journal of Comparative \& Physiological Psychology, 1967.63.549-551.

BRUELL, J. H. Heterotic inheritance of wheelrunning in mice. Journal of Comparative \& Physiological Psychology. $1964,58,159-163$.

BRUELL, J. H. Behavioral heterosis. In $J$ Hirsch (Ed.), Behavior-genetic andysis. New York: McGraw-Hill, 1967.

DeFRIES, J. C.. \& HEGMANN, J. P. Genetic analysis of open-field behavior. In $G$. Lindzey and D. D. Thiessen (Eds.), Contribution to behavior-genetic analysis: The mouse as a prototype. New York: A ppleton-Century-Crofts, 1970

DeFRIES, J. C., HEGMANN, J. P., ROSS D. B., \& HOWARD, M. K. A quantitative behavior of mice. Psychonomic Science $1969,17,153-154$.

DIXON, L. K., \& DeFRIES, J. C. Development of open-field behavior in mice: Effects of age and experience. Developmental Psychobiology, 1968, 1, 100-107.

FOSHEE, D. P., VIERCK, C. J., MEIER, G W., \& FEDERSPIEL, C. Simultaneous measure of general activity and exploratory behavior. Perceptual \& Motor Skills, 1965, 20, 445-451.

FULLER, J. L., \& THOMPSON, R. W. Behavior genetics. New York: Wiley, 1960.

GUTTMAN, R., LIEBLICH, I., \& NAFTALI, G. Variation in activity scores and sequences in two inbred mouse strains, their hybrids, and backcrosses. Animal Behaviour, 1969, 17, 374-385. genetic analysis of change in open-field
LINDQUIST. E. F. Design and andysis of experiments on psychology and education. Boston: Houghton-Mifflin. 1953.

McCLEARN, G. E. The genetics of mouse behavior in novel situations. Journal of Comparative \& Physiological Psychology. $1959,52,62-67$

MCCLEARN, G. E. Strain differences in activity of mice: Influence of illumination. Journal of Comparative \& Physiological Psychology, 1960, 53, 142-143.

McCLEARN, G. E. Genotype and mouse activity. Journal of Comparative \& Physiological Psychology, 1961, 54. 674-676.

MCCLEARN. G. E. Genetics and motivation of the mouse. In W. J. Arnold (Ed.), Vebraska symposium on motivation. Lincoln: University of Nebraska Press, 1968.

MCCLEARN, G, E., \& MEREDITH, w. Dimensional analysis of activity and elimination in a genetically heterogeneous group of mice. Animal Behaviour, 1964 , $12,1-10$.

MCCLEARN, G. E.. \& MEREDITH,W. Behavioral genetics. In P. R. Farnsworth (Ed.), Annual relieu of psychology. Vol. 17. Palo Alto: Annual Reviews. 1966.

MORDKOFF, A. M.. \& FULLER. J. L. Variability in activity within inbred and crossbred mice. Journal of Heredity, $1959,50,6-8$

THOMPSON, $W$. R. The inheritance of behavior: Behavioral differences in fifteen mouse strains. Canadian Journal of Psychology, 1953, 7, 145-155.

THOMPSON, $W$. $R$. The inheritance of behavior: Activity differences in five inbred mouse strains. Journal of Heredity, 1956, 47, 147-148.

VANDERPOOL, D. L.. \& DAVIS, R. T. Differences in spontaneous behavior among inbred strains of mice. Psychological Reports, 1962.10 , 123-130.

WEIR, M. W. \& DeFRIES, J. C. Prenatal maternal influence on behavior in mice. Journal of Comparative \& Physiological Psychology, 1964, 58, 412-417.

WIMER, R E \& FULLER, J. L. Patterns of behavior. In E. L. Green (Ed.), Biology of the laboratory mouse. New York: McGraw-Hill, 1966 .

WINER, B. J. Statistical principles in experimental design. New York: MeGraw-Hill, 1962.

WOLFE, J. L. Exploratory activity and new object response of wild and laboratory house mice Communication in Behavioral Biology, 1969, 4, 13-16. 